\title{
The Integration of Teacher's Pedagogical Content Knowledge Components in Teaching Linear Equation
}

\author{
Yusminah Mohd. Yusof ${ }^{1} \&$ Effandi Zakaria ${ }^{2}$ \\ ${ }^{1}$ Institute of Teacher Education, Islamic Education Campus, Selangor, Malaysia \\ ${ }^{2}$ Faculty of Education, Universiti Kebangsaan Malaysia, Malaysia \\ Correspondence: Effandi Zakaria, Faculty of Education, Universiti Kebangsaan Malaysia, Malaysia. E-mail: \\ effandi@ukm.edu.my
}

Received: April 8, 2015 Accepted: June 5, 2015 Online Published: October 27, 2015

doi:10.5539/ies.v8n11p26 URL: http://dx.doi.org/10.5539/ies.v8n11p26

\begin{abstract}
This qualitative research aimed to explore the integration of the components of pedagogical content knowledge (PCK) in teaching Linear Equation with one unknown. For the purpose of the study, a single local case study with multiple participants was used. The selection of the participants was made based on various criteria: having more than 5 years of experience teaching mathematics and possessing high and low level of knowledge in algebra and high general PCK in mathematics. Six teachers were selected to be the respondents in this research. The data were collected using i) stimulated recall interview, ii) observation, and iii) analysis of documents. Nvivo 8 software was used to help the researcher organize and analyze the data. Kohen Kappa reliability values obtained from three experts were very good, exceeding 0.8 . The findings showed that the integration of content knowledge component of pedagogical implications $(\mathrm{C} \rightarrow \mathrm{P})$ is the most frequently used component in the teaching of Linear Equations with one unknown. This indicates that teachers focus mostly on the components of content knowledge and knowledge about students. The teachers were least likely to integrate content knowledge with pedagogical knowledge, which has implications on the knowledge of the students $(\mathrm{C} \& \mathrm{P} \rightarrow \mathrm{S})$. The study suggests the need to improve teacher's knowledge through collaborative partnership with colleagues and through courses.
\end{abstract}

Keywords: integration component of teacher knowledge, Pedagogical Content Knowledge (PCK), linear equation, teachers' knowledge

\section{Introduction}

In general, basic knowledge and behavior in the classroom are factors that govern any decision to meet the students' aspirations (Posamentier \& Stepelman 1995). In a mathematics class in particular, teachers are expected to play an active role in teaching and learning to change student behavior. To perform this task, each mathematics educator or teacher should have a high knowledge of mathematics (Ball \& Bass, 2000; Ma, 1999) as well as pedagogical knowledge appropriate to the level of their students (Ball et al., 2001; Zawawi, 2003). This supports Ball et al.'s (2001) finding suggesting that the most important factor in determining the outcome of the teaching strategy is the extent to which the strategy used could assist students to experience meaningful learning.

The teaching and learning process requires teacher to possess the components of content knowledge, knowledge of students, as well as different ways in which content knowledge can be applied in the classroom. Shulman (1987) went on to develop the theoretical framework to conceptualize teacher's knowledge that is needed to carry out the process of teaching and learning. This theoretical framework is called Pedagogical Content Knowledge (PCK), which is a combination of content knowledge, knowledge of students, as well as the different ways in which content knowledge can be used in teaching and learning in the classroom (Hill et al. 2004). Although the construct of PCK in education emerged more than 20 years ago, it is still considered useful in educational research because teachers can utilize the knowledge, methods, and goals of PCK to prepare various teaching professional development courses (Abell, 2008). PCK is also a critical element of effective teaching (Lilia et al., 1998). Thus, it can be said that the educational achievement depends on teachers' ability to use pedagogical content knowledge to teach effectively and achieve learning outcomes that meet the objectives of the National Education Philosophy. 


\section{Literature Review}

\section{Pedagogical Content Knowledge (PCK):}

Shulman (1986) referred to pedagogical content knowledge as knowledge about the contents of the topic being taught, a useful representation of the topic, effective analogies, illustrations, examples, explanations and demonstrations, which are useful ways to represents and formulate the content to enhance students' understanding. Pedagogical content knowledge also includes an understanding of what makes learning certain topics easy or difficult, what preconceptions and misconceptions exist among students, and how teachers deal with learning problems. Ball and Bass (2000) argued that pedagogical content knowledge (PCK) is the teacher's ability to transform content knowledge into pedagogical forms that would be effective for all students according to their ability and background.

Gess-Newsome (1999) divided several PCK models that have been produced by several researchers into two groups. One group reflects the Integrative Model, as shown in Figure 1. In this model, PCK is derived based on three different constructs, which are content knowledge, pedagogical knowledge, and context. However, in this research, the context knowledge has been labeled as student knowledge. In this model, the three knowledge types can still be identified and distinguished. PCK exist as a group of several interrelated knowledge types rather than a field of knowledge. Teaching is said to depend on the presentation of educational content in a particular context using appropriate teaching methods. It is the teacher's responsibility to use the components of knowledge content, pedagogical knowledge, and student knowledge and integrate these components to produce effective teaching.

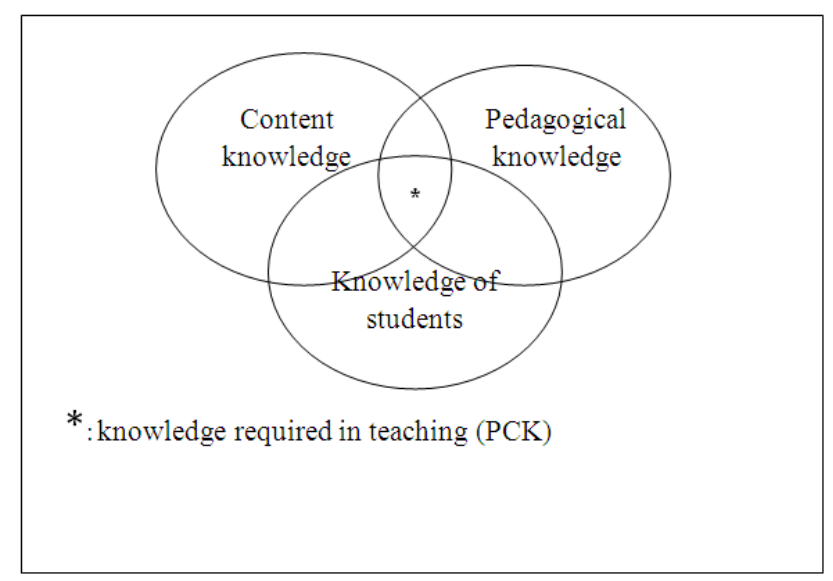

Figure 1. Integrative PCK model (Adapted from Gess-Newsome (1999))

Barker (2007) conducted a study, which focused on the integration of the components of PCK by teachers of mathematics in algebra. Barker (2007) studied two teachers from a specific topic of algebra at the primary school level. The study showed that student knowledge has the largest implication on the actions carried out by the teacher. The integration of the components of PCK, which are the knowledge of content, pedagogical knowledge, and knowledge of the curriculum, has implications on teaching, interpretation of students' thinking, and the students. The explanation given by the teachers in providing the rationale for their actions was mainly focused on two components of knowledge: knowledge of students and knowledge of pedagogy and curriculum. This finding supports the statement that content knowledge alone could not ensure the effectiveness of teaching (Barker, 2007; Kahan et al., 2003). It is believed that teacher focuses on students' knowledge components to provide justification for their actions in teaching (Barker, 2007). Meanwhile, students' achievement in algebra in Malaysia is still low compared to their achievement in other subjects, such as numbers, geometry, data, and probability (TIMSS 2007, 2009). Thus, the current research is relevant, as it focuses on teaching algebra.

\section{Purpose of Study}

The knowledge of what happens in the process of teaching and learning can improve our understanding of and explain the phenomenon of learning problems that students face. This study is able to contribute to the development of teaching profession based on the knowledge of the teacher and the way in which he/she can utilize this knowledge in classroom. Therefore, this study explored how teachers integrate knowledge 
components of PCK in their classrooms. Three components of PCK include knowledge of content, pedagogical knowledge, and knowledge of students. The teacher focused on teaching the topic of Linear Equations in one unknown

\section{Methodology}

This study focused on the teaching and learning in the classroom. It is also known that experienced teachers will focus more on students rather than classroom management and themselves (Cavanagh \& Prescott, 2007). Therefore, to fulfill this purpose, the teachers who have been teaching mathematics for five years or more were counted as participants. Six teachers from three schools were willing to be participants in the study and they met the selection criteria specified. All participants of this study also scored moderately high and high on mathematics PCK questionnaire, with average score of 3 out of 4 on all dimensions of mathematics education and mathematics teaching strategy dimensions. This study utilized the questionnaire developed by Zawawi (2005). This case study used three data collection techniques, specifically stimulated recall interview; observation of teaching in the classroom; and the analysis of documents, such as textbooks, teacher lesson plans, and student training answers. Teaching episodes in the observation sessions were used in the stimulated recall interviews sessions. Protocol adapted from Barker (2007) with the proposed implementation of the stimulated recall interviews by Shekedi (2005) were prepared to help researchers administer the interviews efficiently. As the interviews were conducted with reference to the teaching sessions that had been implemented, some questions were specific to each participant. This happened when asking teachers to explain what and why they used certain activities in their teaching.

\section{Data Analysis}

The researcher analyzed the data collected in response to the research question "How do teachers integrate knowledge component when teaching Linear Equations?" by referring to the data obtained from stimulated recall interviews. To obtain a clear understanding of teachers' PCK, the researcher had to refer to the transcription of stimulated recall interviews as well as the transcription of teaching observations. The transcriptions of the interviews were then analyzed based on the components of PCK knowledge by labeling the items with specific codes representing mathematics content knowledge (C), knowledge of the pupils (M), and pedagogical knowledge $(\mathrm{P})$ derived from the synthesis of the literature that has been conducted in this area. The PCK definitions are summarized in Table 1.

Table 1. Definitions of PCK teacher knowledge component

Mathematics content knowledge

Teacher discusses a topic related to the linear equations, including any relation among mathematical ideas in this topic. The discussion focuses on the content of mathematics, teachers' views of this topic and mathematics, and the usefulness of this topic in learning mathematics

Pedagogical knowledge

Teachers talked about a math activity, and the questions posed by teachers to direct teaching and learning. Teacher's comments focused on the implementation and teaching arrangements in this topic and the materials used. Any comments regarding the curriculum or the syllabus and examination also fall under in this definition.

Knowledge of students

Teachers' comments on anything related to thinking and students' learning, including understanding, misconceptions, and students difficulties and students' prior knowledge. Teacher's comments focused on students.

Table 1 provides definitions of each knowledge component. Sample analysis results are shown in Figure 2 below. 


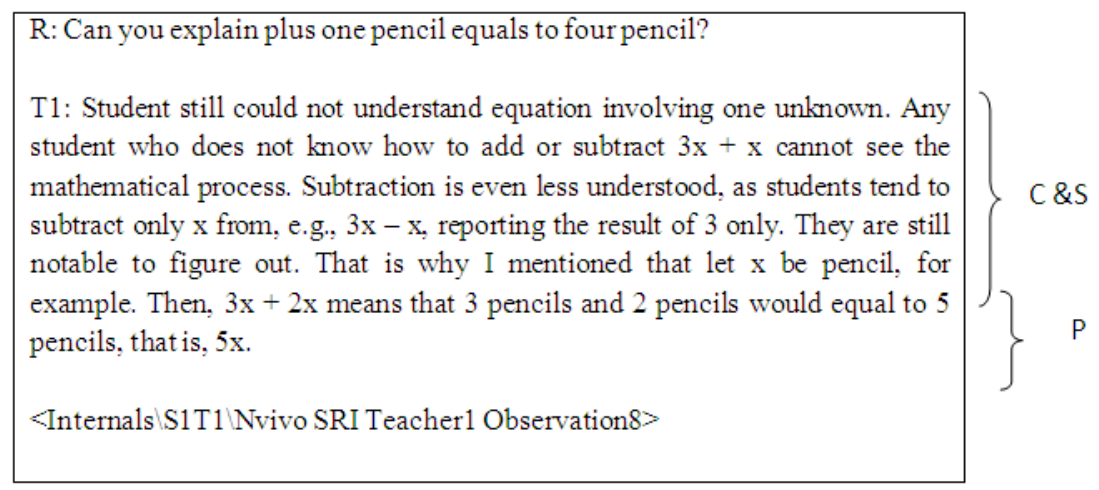

Figure 2. Example of the integration of teacher knowledge component

In the excerpt, the teacher has demonstrated a combination of knowledge about the content and students' understanding of the content. Teacher mentioned the use of $\mathrm{x}$ as the unknown in algebra's terms and indicated that it is difficult for students to grasp the concept of the operation involving algebra's term. This example is coded as content knowledge and knowledge of students. The combination of teacher's knowledge influenced the teacher's action by providing concrete examples of analogies to enhance students' understanding of the addition operation of similar term. Thus, teacher's explanations are categorized under the theme of content knowledge and knowledge about students $(\mathrm{C} \& \mathrm{~S})$, which have implications for pedagogy $(\mathrm{P})$. This relationship is labeled as $(\mathrm{C} \& \mathrm{~S} \rightarrow \mathrm{P})$.

\section{Findings}

The integration of teachers' knowledge components reflects five themes. The theme with the highest frequency is the integration of content knowledge, which influences the pedagogical implications $(C \rightarrow P)$, followed by the integration of content knowledge and knowledge about students, which have implications on the pedagogical knowledge $(C \& S \rightarrow P)$. Another theme that emerged was the integration between the components of content knowledge, knowledge of students, and pedagogical knowledge (C\&S\&P), the integration between the components of content knowledge and pedagogical knowledge that have implications on the knowledge of the students $(\mathrm{C} \& \mathrm{P} \rightarrow \mathrm{S})$, and finally the integration among the components of students' knowledge of the implications of the content knowledge and pedagogical knowledge $(S \rightarrow C \& P)$. The knowledge of the content being taught to students is emphasized in the course syllabus. The knowledge of the students is categorized into several themes, namely students' prior knowledge, students' problems, students' weaknesses, students' mistakes, and students' mastery skills. The themes that emerged in pedagogical knowledge represented various examples that teachers use in their class, such as making analogies, establishing relations with numerical or concrete examples, and correcting students' mistakes. The relations among PCK components are displayed in Table 2 below.

Table 2. Relations among PCK components in the teaching linear equation

\begin{tabular}{lc}
\hline Integration of Knowledge Content & Total Frequency \\
\hline $\mathrm{C} \rightarrow \mathrm{P}$ & 74 \\
$\mathrm{C} \& S \rightarrow \mathrm{P}$ & 56 \\
$\mathrm{C} \& S \& \mathrm{P}$ & 22 \\
$\mathrm{C} \& \mathrm{P} \rightarrow \mathrm{S}$ & 11 \\
$\mathrm{~S} \rightarrow \mathrm{C} \& \mathrm{P}$ & 13 \\
Total & 176 \\
\hline
\end{tabular}

The knowledge of content has implications for pedagogy $(C \rightarrow P)$, and it is the most frequently used theme, i.e., the teacher's explanations are focused on the content knowledge of the Linear Equations subject. These conditions can be seen from the terms used to form a linear algebra equation. The sixth observation session demonstrated that the teacher began the lesson by writing the definition of linear algebra terms on the chalkboard, 
that is, "A linear algebraic terms consists of only one unknown, which is to the power of $1 . "$ He then gave examples to clarify these terms. He continued the lesson by giving linear algebra expression to explain to the students that each term in the expression must include linear algebra terms. Such explanation demonstrates teacher's pedagogical knowledge. The teacher's explanation reflects the integration of two components, which are content knowledge and pedagogical knowledge $(\mathrm{C} \rightarrow \mathrm{P})$.

A similar observation was recorded for the second highest theme that emerged. Teacher 3 stated that students already know commonly used equation symbols but do not understand non-equation symbol used in Linear Equations topic that is part of the content knowledge and knowledge about students (C\&S). Thus, based on this knowledge, the teacher provided an example to illustrate the non-equation symbol " $\neq$ " through comparing non-similar entities, male vs. female (pedagogical knowledge, P). This model was also chosen to explain the concept of inequality because teachers felt that students understand these examples easily. Thus, in introducing the concept of equality, which focuses on the symbols used, the integration of these $(\mathrm{C} \& \mathrm{~S} \rightarrow \mathrm{P})$ suggests that teachers awareness of students" prior knowledge of the contents, namely the equation symbol "=", influenced the teachers to further introduce the symbol " $\neq$ ".

The influence of students' knowledge on the pedagogical content knowledge and teachers' pedagogical knowledge $(S \rightarrow C \& P)$ yielded the least number of themes. This relationship suggests that the teacher presented something related to the knowledge of the students, such as students' prior knowledge, the students' problem, mistakes or misunderstanding about something, which could later influence the knowledge of content and pedagogy. Knowledge of content and pedagogy can be derived from the content that takes into account teacher's knowledge of the students. For example, teacher 3 stated the following when delivering content to determine whether a given value is the answer to the linear equation:

T3: Sometimes we have to show that too, so follow the textbook. In fact, if we continue what we used to do, we sometimes skip one stage. It means the boy did not know why that thing happens. It is so sudden. He did not ask but he does not understand that thing. When he did not understand and could not understand, then he easily forgets. We want him to understand. Meaningful learning is OK. That's why we follow this textbook, we show them this step before they learn to solve linear equations. Specify whether this value is the answer to the given equation.

$<$ Internals $\backslash$ S1G3 $\backslash$ Nvivo SRI Teacher3 Observation 9>

In the $9^{\text {th }}$ observation, Teacher 3 introduced the skills to determine the answer to a given linear equation by substituting the numerical values listed. In the interview, Teacher 3 stated that the students would not be able to solve linear equations without specific skills taught by the teacher, which demonstrate teachers' knowledge of the students. Thus, Teacher 3 believes that it is necessary to teach the students the skills by replacing the numerical values in order to determine the answer to Linear Equations in the textbook (knowledge of content and pedagogy). Thus, the teacher's explanations have implications for knowledge of the student towards pedagogical and content knowledge of the teacher $(S \rightarrow C \& P)$.

\section{Discussion}

The study found that the most frequent theme underlying the teachers' knowledge component involves the integration of content knowledge with pedagogical knowledge $(C \rightarrow P)$, where teachers talk about mathematics content and its delivery to students. This theme emerged 74 times. This is may be because the topic of Linear Equations is new and requires finding unknown values. Although this topic focuses on finding the solution, the skills in collecting similar unknown in algebraic terms is still needed. However, teachers lacked the skills in relating the topic to the knowledge of the pupils. Teachers stated that the topic of Linear Equations focuses only on one unknown to the power of one; thus, students did not encounter any problem in collecting similar unknowns. Therefore, the teachers talked most frequently about the content and its presentation to the students.

In addition, the integration of content knowledge with pedagogical component influences the knowledge of the students $(\mathrm{CS} \& \mathrm{P} \rightarrow \mathrm{M})$. Knowledge of the students has implications on knowledge of content and pedagogy $(\mathrm{S} \rightarrow \mathrm{C} \& \mathrm{P})$, although this relation emerged least frequently among the participants, with the frequencies of 11 and 10 respectively. Meanwhile, other three participants did not show that the integration of content and pedagogy has implications on knowledge about students $(\mathrm{C} \& \mathrm{P} \rightarrow \mathrm{S})$. The diagram below contains a thick and dashed arrow and a thick circle to further illustrate the previous relationship. The summary of the integration of knowledge components in teaching linear equations id illustrated in Figure 3 below. 


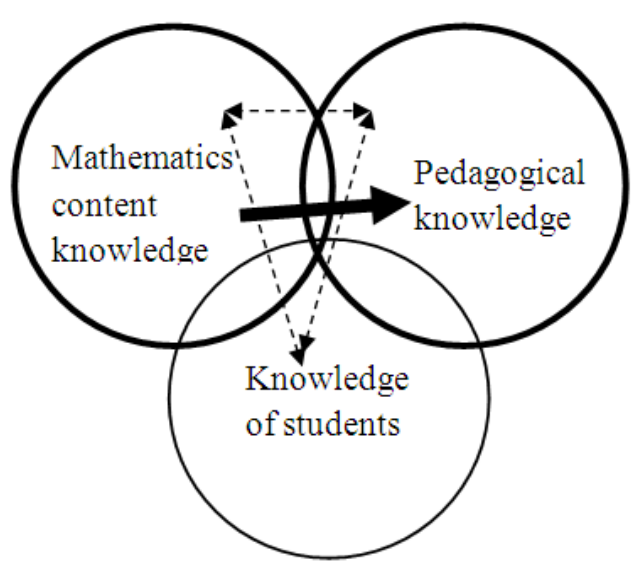

Figure 3. The integration of teacher's PCK components in teaching linear equation

These findings support the findings of previous researchers, such as Barker (2007), Shah (2006), and Zaidah (2005), who stated that teachers incorporate these knowledge components interactively when teaching. The integration of knowledge components also supports Gess-Newsome (1999), who stated that PCK combines the content knowledge and pedagogical knowledge components. In this study, teacher explained his actions by focusing on content knowledge together with knowledge of the students, which is not consistent with the findings Even and Tirosh (1995) who looked at the influence of content knowledge and knowledge of the students on the actions of teachers in teaching. In their study, teachers' knowledge of content rather than teachers' knowledge of students influenced teaching arrangements. However, these findings were in line with the findings made by Zaidah (2005) who found that experienced teachers adapt their teaching methods based on their knowledge of the students. Similarly, Barker (2007) also found that the knowledge of the students dominates teachers' action in the classroom.

The linear equation lessons also showed that knowledge of content has implications on teachers' pedagogical knowledge. Teachers focus on the content and the approach without the explicitly mentioning the knowledge of the students. By neglecting the knowledge of students, the implementation of more effective teaching could be affected. This is because knowledge of the pupils' cognition is an important component. Learning is what happens in the classroom, which is what students are doing in their learning environment (Fennema \& Franke, 1992). Knowledge of students and knowledge of various teaching approach reflect pedagogical content knowledge (Sibel, 2007). Thus, the lessons carried out in this study did not emphasize one of the activities proposed by the PPK (2006), which is the constructivist approach in which students are taught to develop their own mathematical knowledge.

The opportunities in teaching linear equations should not be taken for granted, as the topic provides students with the opportunity to solve problems. Various situations in daily life problems are specifically related to the concepts of algebra. Piaget stated that any new experience that has the element of challenge can stimulate cognitive development. The development of the cognitive structure could not materialize if only assimilation process takes place. A teacher should determine the level of cognitive structure for each individual student and gradually change the structure (Olson \& Hergenhahn, 2009).

\section{Conclusions}

Teachers need to utilize the results of studies based on teachers' knowledge to interpret students' conceptions and misconceptions of mathematical ideas or to form and develop a more effective method of teaching. Teachers are able to change teaching approaches when they understand students' thinking strategies, to reflect and discuss their teaching, and to cooperate with their colleagues by considering professional development as one of the important aspect in the organization. This is consistent with the recommendation made by NCTM (2000) that emphasizes the importance of professional development, which is considered a long-term career process of a teacher. Therefore, the duty of every mathematics teacher is to enhance his or her knowledge through participation in professional development activities. Teachers' professional development should be a lifelong learning process so that teaching practices can lead to effective learning outcomes. 


\section{References}

Abell, S. K. (2008). Twenty Years Later: Does pedagogical content knowledge remain a useful idea? International Journal of Science Education, $30(10), \quad$ 1405-1416. http://dx.doi.org/10.1080/09500690802187041

Ball, D. L., \& Bass, H. (2000). Interweaving Content and Pedagogy in Teaching and Kearning to Teach: Knowing and Using Mathematics. In. J. Boaler (Ed.), Multiple Perspective on Mathematics Teaching and Learning. Westport, CT: Ablex Publishing.

Ball, D. L., Lubinski, S. T., \& Mewborn, D. S. (2001). Research on teaching mathematics: The unsolved problem of teachers' mathematical knowledge. In. V. Richardson (Ed.), Handbook of Research on Teaching (4th. ed., pp. 433-456). New York: Macmillan.

Barker, D. D. (2007). Teachers' knowledge of algebraic reasoning: its organization for instruction (Unpublished doctoral dissertation). University of Missouri, Columbia.

Bobis, J., \& Anderson, J. (2007). Reform-oriented teaching practices and the influence of school context. Proceedings of the $30^{\text {th }}$ Annual Conference of the Mathematics Education Research Group of Australasia.

Cavanagh, M., \& Prescott, A. (2007). Professional experience in learning to teach secondary mathematics: Incorporating pre-service teachers into a community of practice. Proceedings of the $30^{\text {th }}$ annual conference of the mathematics Education Research Group of Australasia.

Curriculum Development Centre. (2006). Integrated Curriculum for Secondary Schools. Curriculum Specifications. Mathematics. Ministry of Education. Malaysia.

Fennema, E., \& Franke, M. L. (1992). Teachers' knowledge and its impact. In. D. A. Grouws (Ed.), Handbook of Research in Mathematics Teaching and Learning (pp. 147-164). Reston, VA: National Council of Teachers of Mathematics.

Gess-Newsome, J. (1999). Pedagogical content knowledge: An introduction and orientation. In. J. Gess-Newsome, \& N. G. Lederman (Eds.), Examining Pedagogical Content Knowledge (pp. 3-17). Dordrecht, Netherlands: Kluwer Academic Publishers.

Hiebert, J., \& Grouws, D. A. (2007). Effective teaching for the development of skill and conceptual understanding of number: What is most effective? National Council of Teachers of Mathematics.

Hiebert, J., Gallimore, R., \& Stigler, J. W. (2002). A knowledge base for the teaching profesion: What would it look like and how can we get one? Educational Researcher, 31(5), 3-15. http://dx.doi.org/10.3102/0013189X031005003

Hill, H. C., \& Ball, D. L. (2004). Learning mathematics for teaching: Results from California's mathematics professional development institutes. Journal for Research in Mathematics Education, 35(5), 330-351. http://dx.doi.org/10.2307/30034819

Kahan, J. A., Cooper, D. A., \& Bethea, K. A. (2003). The role of mathematics teachers' content knowledge in their teaching: A framework for research applied to a study of student teachers. Journal of Mathematics Teacher Education, 6, 223-252. http://dx.doi.org/10.1023/A:1025175812582

Lesser, L. M. (2001). Algebra for All. Reunion of broken parts: Experiencing diversity in algebra. The Mathematics Teacher (pp.62-66).

Lilia, H., Abd-Rashid, J., Meerah, T. S. M., Abd-Razak, H., \& Khalid, A. (1998). Development of pedagogical content knowledge through implicit and explisit teaching. Report of a Study. Faculty of Education. UKM

National Council of Teachers of Mathematics. (2000). Professional standards for teaching mathematics. New York: NCTM.

Noor, S. S. (2006). Pedagogical content knowledge and its practices among secondary school mathematics teachers (Unpublished doctoral thesis). Universiti Kebangsaan Malaysia

Noor, S. S. (2009). Mathematics students teachers' pedagogical content knowledge in the context of teacher education programs. In O. De Jong, \& L. Halim (Eds.), Teachers' Professional Knowledge in Science and Mathematicss Education: Views From Malaysia and Abroad. Faculty of Education, UKM.

Olson, M. H., \& Hergenhahn, B. R. (2009). An introduction to theories of learning (8th ed.). NJ: Prentice Hall.

Posamentier, A. S., \& Stepelman, J. (1995). Teaching Secondary School Mathematics: Techniques and Enrichment Units. Columbus, Ohio: Merrill-Prentice Hall. 
Shekedi, A. (2005). Multiple Case Narrative: A Qualitative Approach to Studying Multiple Populations. Philadelphia: John Benjamins Pub. http://dx.doi.org/10.1075/sin.7

Shulman, L. S. (1986). Those who understand: Knowledge growth in teaching. Educational Researcher, 15(2), 4-14. http://dx.doi.org/10.3102/0013189X015002004

Shulman, L. S. (1987). Knowledge and teaching: Foundations of the new reform. Harvard Educational Review, 57(1), 1-22. http://dx.doi.org/10.17763/haer.57.1.j463w79r56455411

Zaidah, Y. (2005). Pedagogical content knowledge of additional mathematics teachers (Unpublished doctoral thesis). Universiti Kebangsaan Malaysia.

Zawawi, Z. (2005). Pedagogical content knowledge of primary school mathematics teachers (Unpublished doctoral thesis). UniversitiKebangsaan Malaysia.

\section{Copyrights}

Copyright for this article is retained by the author(s), with first publication rights granted to the journal.

This is an open-access article distributed under the terms and conditions of the Creative Commons Attribution license (http://creativecommons.org/licenses/by/3.0/). 